\title{
9. Quotidian Care at a Distance
}

\begin{abstract}
Chapter 9 explores how some of these practices are playing out for our participants and how this informs generational imaginaries around data for care at a distance. How can we map and learn from some of the informal media methods for care at a distance around supporting older adult's independence and social inclusion? And how can understanding intergenerational emerging practices provide insight to that complicate definitions of datafication and dataveillance (using data to watch people)?
\end{abstract}

Keywords: informal care; care at a distance; social inclusion; aging

In this chapter, we focus on participants' practices and perceptions in and around Co-futuring Kinship through the idea of quotidian care at a distance. Co-futuring requires us to navigate the ways in which lived experiences are narrated in and through processes of the past, present and future. Understanding this complex and dynamic narrative requires us to acknowledge the ways in which intergenerational perspectives of care create multiple ways of being in the world. How does the data we make today impact upon how we reflect upon future notions of self? How can we make careful data? How are people starting to think about what data trails they will leave for their loved ones when they die? Aspects of Co-futuring Kinship recognize that the stories that we make of the world are a combination of experiences of the past and present projected onto feelings of the future.

We begin with Japan, deemed a super-aging country - that is, one quarter of the population are over 65 years old (OCED 2019). Many countries are turning to locations such as Japan to see how they address super-aging. What can we learn from Japan? What lessons are transferrable? What are culturally-specific? While images of robots or AI in aged homes dominate press media, the everyday Japan is much more mundane in its deployment of methods for care at a distance. We then turn to fieldwork in Shanghai and Melbourne to further reflect upon the cultural differences and parallels.

Hjorth, L., K. Ohashi, J. Sinanan, H. Horst, S. Pink, F. Kato, B. Zhou, Digital Media Practices in Households: Kinship through Data. Amsterdam: Amsterdam University Press, 2020 DOI 10.5117/9789462989504_CHo9 
There are many particular features to the Japanese super-aging context which are culturally, technologically and spiritually specific. For example, in rural Japan in which dying towns are growing, the deployment of automated cars to drop off groceries to older adults in remote mountain areas is becoming reality. Risks of older adults driving recklessly were heightened in April 2019 with the accident involving an 87-year-old driver, who ran off road out of control and killed a mother and child, as well as injuring 10 others (Inagaki 2019). With over 50\% of road fatalities caused by elderly drivers, there is a mounting case for driverless cars in Japan. Companies like Toyota are working with researchers and older adults to explore perceptions and practices given that much of the early work into driverless cars has been in urban areas. Issues such as network coverage and low consumer acceptance are but a few of the concerns.

In Japan, the average life expectancy is 87 for females and 81 years old for males (Ministry of Health, Labour and Welfare of Japan 2018). Even though Japan leads the rest of the world in life expectancy, there is a gap between the average life expectancy and healthy life expectancy (WHO 2016). In Japan, healthy life expectancy is 75 for women and 72 for men. This means that there is a decade in which dependency and decline affect quality of life. In a study conducted over two decades with 6000 participants, Akiyama found that about $80 \%$ of the older adults start to decline in health in their mid-seventies and need some kind of care (2000).

One of the key issues for prolonging healthy life is the prevention of frailty (Iwasaki 2017). Iwasaki describes "frailty" as the state between good health and need for personalized care. As a concept it covers physical, mental and psychological and social issues. For Iwasaki, frailty can be resolved with appropriate intervention. For Iijima (2016), there is a need to understand frailty as having three key aspects- physical, mental and social.

One of the key issues regarding aging well is social inclusion. Here media like Pokémon $G O$ that encourage social cooperation as part of their game play can be playful ways to combat these issues (Hjorth and Jimenez 2019). In Japanese press media, koritsu-shi (solitary death) cases have received significant attention due to the increase in single-person households (Kanawaku 2018). Kanawaku explains that often kodoku-shi (lonely death) is conflated with koritsu-shi (solitary death). For Kiwaki et al. (2015) the rise of loneliness/ social isolation in older adults has grown out of lifestyle shifts in post WWII Japan, in which adult children no longer live with their older parents to help with informal forms of care. 


\section{Informal Care}

As mentioned in Chapter 1, Pols's notion of care at a distance is useful in conceptualizing the way in which intergenerational care and digital media are playing out (2012). While Pols spoke of formal contexts of care in the case of palliative care, we reflect upon the often unspoken and mundane aspects of informal care in the home. Here, we argue, the role of mobile media (and its attendant datafication) can help to provide an ambient sense of autonomy from a distance - what we called "friendly surveillance" (see Chapter 1 and 3).

In contemporary Japan we are starting to see emerging forms of informal care and housing that no longer adhere to traditional familial ties. Instead, we are seeing new forms of Co-futuring Kinship. As argued in Chapter 1 and 2 , the digital plays a key role in creating continuity, rather than disruption, in practices of kinship. We illustrated that through the context of LINE (Chapter 2), familial kinship can be reinforced through digital relations. Moreover, the digital can also create forms of kinship between non familial members.

Take, for example, 37-year-old female graduate student Akiko who had divorced her husband and lived in a shared house with a cat "Mii" in the Tokyo metropolitan area. In the shared household there also lived an older administrative woman in her 6os and a graduate student at the same university. Her parents lived in the Tohoku district. To come back to her parents' home, it took over three hours from Tokyo by airplane or Shinkansen (bullet train). Her parents used to run a construction company for years but they semi-retired when Akiko's older brother inherited a business several years ago. Her father Masaru, 73-year-old, traveled to a local hospital but also a special hospital in Tokyo several times a year because of kidney disease. Her 68-year-old mother Yoshie was healthy and supported her husband for a long time.

However, Yoshie went to hospital for pneumonia. Masaru was a typical traditional husband who was committed to his work and left all housework and childcare matters to his wife. For Akiko, Yoshie was a "super woman" who managed housework, childcare and supported their family business. If something happened to Yoshie, Masaru wouldn't cope. Once Masaru called Akiko at five in the morning to come back home. He said, "Mother might die so come home." Yoshie survived but the incident highlighted how much Masaru depended on Yoshie. Akiko's brother, Kouichi, helped with parents' daily life when he wasn't busy managing the business. 
Given the circumstances, Akiko decided to come home more frequently to take care of her parents. Things had changed a lot from when Akiko used to live in Tokyo with her ex-husband. But since the divorce and her parents' decline in health, Akiko had to make a few big changes in her life to ensure that her parents are cared for. When Akiko wasn't there, she kept a friendly eye on Yoshie through LINE. Kouichi's children taught Yoshie to use her smartphone and LINE. Yoshie was always looking forward to seeing Akiko's life in Tokyo on Facebook and LINE. Akiko was mindful of what she chose to select and share with her mum.

For Yoshie, seeing Akiko with a job and research made her happy. Yoshie sent messages and stamps on LINE to Akiko as soon as she read Akiko's posts. Akiko felt that it had become a great deal easier to get in touch with her mother after she started to use LINE. Calling was sometimes bothersome. But on LINE it was easy to share mundane matters and fleeting feelings. For Akiko, the stamp feature of LINE was most useful as it enabled them to easily “confirm the existence of each other." Initially Akiko didn't like LINE that much, however, the cuteness of the stamp "softened" the communication between her and her mother — which allowed for informal care at a distance.

As discussed in Chapter 2, the rise of paralinguistics allows for new ways to articulate emotional and often tacit ways of caring at a distance. This new vernacular can allow for intergenerational modes of care to be fostered. Paralinguistics in the form of LINE stamps allows for playful experiences between mother and daughter. As Yoshie said in one post, "It's fun to send you stamps. This stamp reminds me of your childhood." Akiko said, "I am 37 years old now!!” Yoshie says “I know ... I am an annoying mother...”

37-year-old Serika, who worked in an advertising agency, had a different story about care at a distance. She lived in the Tokyo metropolitan area with her husband and was expecting their first baby in six months. Serika's parents were divorced but she had a good relationship both with her father and mother. Her father had been struggling with cancer for two years and was now in hospital at the terminal stage. Serika, his only daughter, traveled to hospital to take care of him on a regular basis.

As part of her job, Serika used smartphone apps. But, for a long time, she resisted using them in private life. She still used SMS to keep in contact with her husband. For Serika, she hoped for a watching camera app for babies and so she could give her 74-year-old father Kunio a way to be part of the baby's life during his last stages of cancer in which he was bed-ridden. Serika thought that these kinds of watching systems could help foster a sense of safety, especially with more older adults who lived alone. Serika said "seeing 


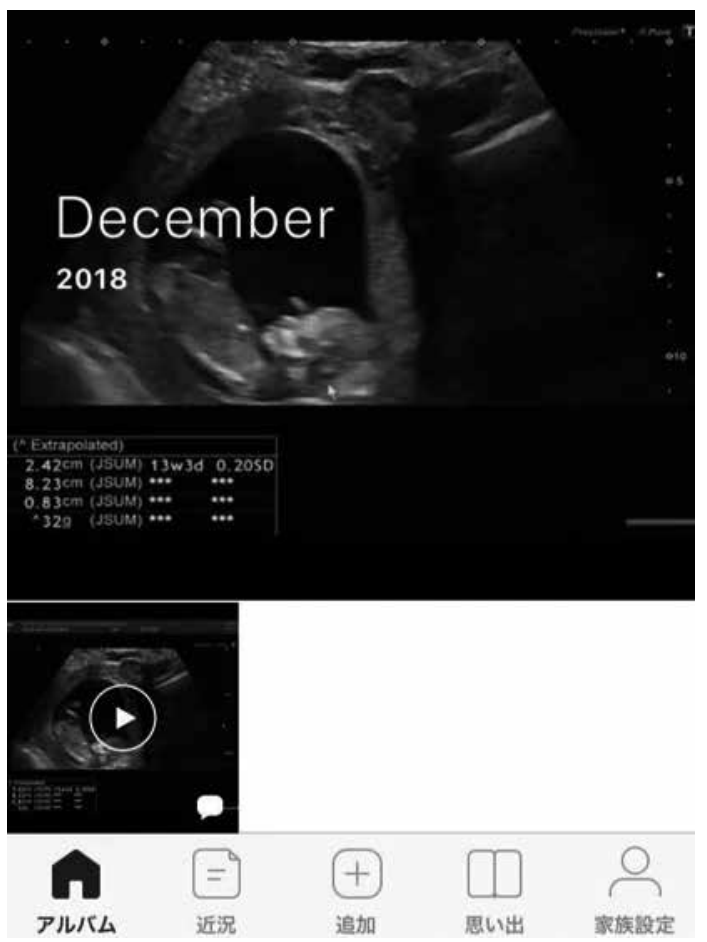

Figure 9.1: A moving echo image of the embryo provided by the gynecologist and shared with Serika's family members on Mitene

can create relief." For Serika, visual information had become increasingly essential for families who lived separately.

Recently Serika started to use a family album app "Mitene" (take a look) as recommended by the hospital. It enabled Serika to share an image of her embryo sent by the gynecologist among family members who registered in the app. The app recorded the baby's growth by picture or moving image, which enabled other family members to watch the baby's growth at a distance. This phenomenon is what Tama Leaver calls intimate surveillance (2017) - a practice that has, according to Leaver, ramifications for future generations in terms of digital legacy and data control.

\section{Digital Care}

Although Akiko still felt young, the idea of dying alone frightened her. Even though she lived in a shared house, she hardly saw her housemates. Akiko 


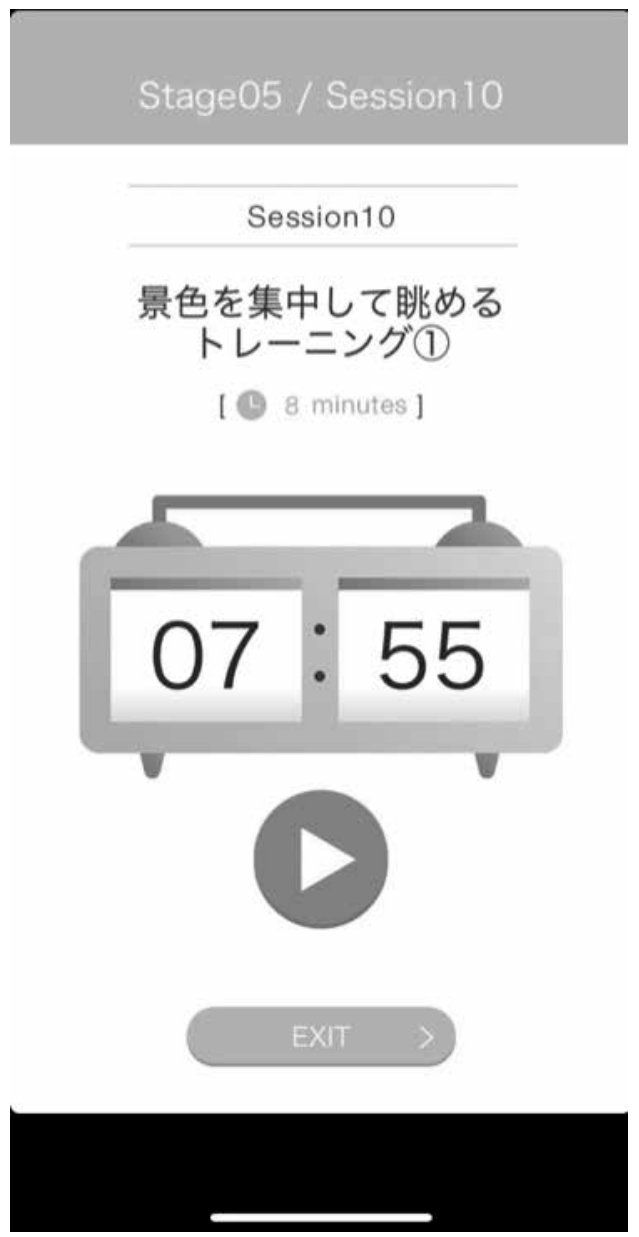

Figure 9.2: Screenshot of a meditation app, which gives instructions according to the user's heart rate. The text translates to "training to look outside with concentration"

became interested in buying an Apple Watch to help monitor her health and heart-rates. She also started using a meditation app to help with anxiety and stress issues. After facial registration occurred using the camera, the app automatically measured heart rate and gave instructions for something that must be done in relation to these biometrics. When thinking about mobile apps, Akiko hoped that the digital data about her body might provide new understandings into her health.

Like Akiko, Serika also liked the idea of an online doctor who diagnosed based on facial recognition via phone camera or advised according to biological data through an app. Serika had used a few apps for monitoring 
health - an app which forecasted ovulation according to body temperature (when she was taking infertility treatment) and also an app for weight control.

Since becoming pregnant, Serika used her smartphone constantly to look up facts about giving birthing and childcare. If she had morning sickness or some such condition, she researched it using her phone. She found it gave her more relief than a book or asking another person. Serika liked that she could search different responses and conditions in detail, commenting that "the smartphone is like a teacher about childcare for me." She noted that she relied on the phone because she didn't live with her mother. Getting online was faster. For Serika, as an expectant mother, she used the phone like a doctor-monitoring her child's health and notifying her of any concerns.

For Serika's 74-year-old mother Yurie, "digital health" had a different meaning. She was new to smartphones having only purchased recently. Living with her grandson, Yurie had learnt to use LINE from him. For Yurie, social media like Facebook and Instagram concerned her-she felt strangers would invade her privacy. Recently she had hurt her back and found herself using the new smartphone for enjoying drama on Netflix and contacting friends on LINE. And so, for Yurie "digital health" entailed maintaining mental health by using the smartphone for entertainment and communication with her close friends and family members.

Similarly, Yurie's 73-year-old friend Masami uses tablet PC for entertainment. After getting divorced in her 40s, she worked as a full-time until her late 6os. She retired at 70 when she started to feel she had less energy and strength. At that time, she also gave up driving. Since then, Masami often spent her time at home. On weekdays she went to an orthopedic doctor twice a week to care of her knee and to a culture center to learn Japanese calligraphy once a week. She also sometimes went out for lunch with her friends or her daughter. Otherwise, Masami watched TV at home. Her son recommended she play the game reversi on tablet PC to help prevent cognitive decline. This was her first tablet experience. Even though smartphones were attractive, Masami thought they looked difficult and so preferred to use her featured phone. In the beginning, she felt confused about how to use it - gradually she mastered it and enjoyed playing games. Getting a higher score brought her joy and she felt satisfaction. She also liked the idea that the game was helping her cognitive health.

Retired 64-year-old Hiroshi also used digital media to maintain his mental and physical health. He was very interested in new technologies such as mobile devices and the smartphone because of his previous job. Hiroshi had been an iPhone owner since its release in Japan. Hiroshi used various apps - such as LINE, weather forecast, and an app provided by his town which reminded him of garbage collection day. In addition to his iPhone 


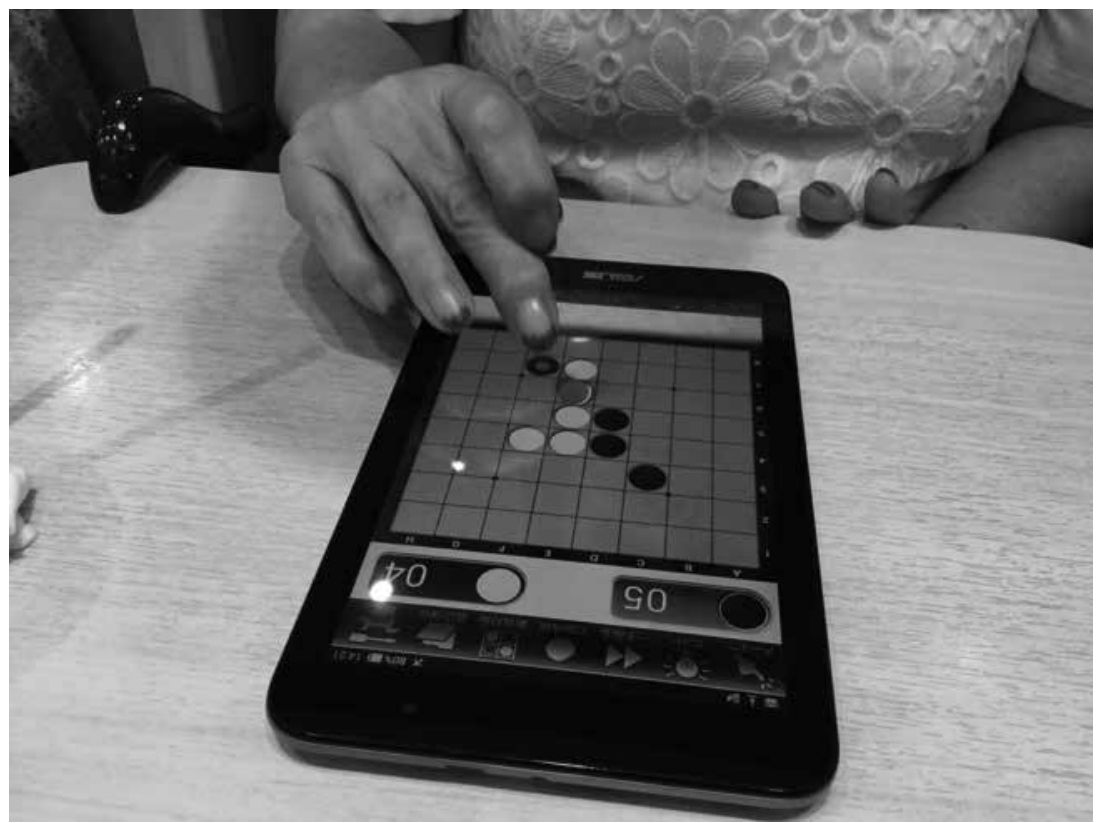

Figure 9.3: Masami is playing game, reversi, on tablet PC

Hiroshi had an Apple Watch to check his schedule and to monitor his daily exercise. He liked playing games but preferred to play on the bigger desktop computer screen. Hiroshi played simple games like Tetris and solitaire. Hiroshi admitted "I cannot play young people's games.”

While Hiroshi enjoyed the more retro games, he was mindful of their role in helping to maintain cognitive health. As someone that previously worked in media (at a cable television company), Hiroshi enjoyed the role of technology for relaxation and reflection. Here he differed from some of our female participants in his age group as he didn't use the technology very much for socializing.

Through our fieldwork in Tokyo we developed insights into some of the complex and ambivalent ways in which intergenerational care is playing out in different data trails. While younger participants talk more about present practices and perceptions about the future almost seemingly, our older participants seemed much more circumspect in their observations. Moreover, there still seemed to be some implicit notions of agism with the intergenerational discussions around technology. However, the use of mobile apps for care at a distance cannot be underestimated.

There was also less concern around the role of data and digital legacy than in the Shanghai and Melbourne contexts. In Japan, this was partly to 


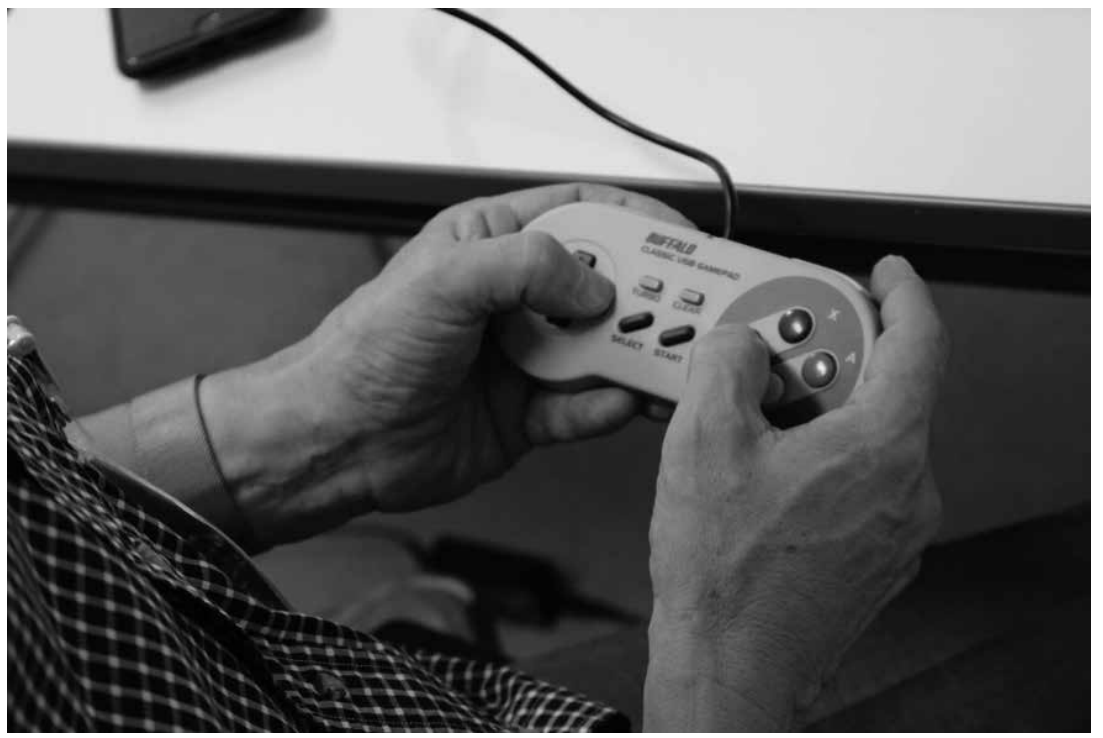

Figure 9.4: Hiroshi likes playing "old" games on desktop computer

do with underlying Buddhist spiritualism whereby this life is conceived as one in many. It was also due to the lack of palpable impact of data trust scandals (i.e. NHK Fukushima disaster cover up) in Japan in which social media like LINE, rather than Facebook, dominate.

In our Japanese fieldwork, the growing role of technology to assist the burgeoning super-aging populations was undeniable. As aforementioned, much of the emergent technology work was grappling with phenomenon such as aging populations in remote areas. The use of AI robots in aged care facilities to explore alternative care scenarios was a growing field of research and practice (Yamazaki et al. 2018). AI Robots like Hiroshi Ishiguro's "Telenoid" were being pivoted in dementia care settings to see if robots could help with memory and sociality. While STS scholars such Judy Wajcman rightly argue that robots and AI will never be able to master the slow and mundane rituals of care that humans do so well, how they operate in intermediary ways - even if to just give reprieve to care workers - will continue to be questioned into our Co-futuring Kinship.

\section{WeChat and Informal Care}

In Shanghai we find parallel practices emerging. While not experiencing super-aging yet, the country's thirty year one-child policy is starting 
to have ramifications in caring for older adults. With only one child to care and work, stress on informal care systems will begin to grow. Moreover, with the rise of technological surveillance being used by the government to implement automated issues such as social credit, the role of smartphones for self-tracking such as monitoring health takes on different dimensions.

According to the statistics of China's National Bureau of Statistics, there are about 240 million elderly people in China over 60 years old, and about 160 million people over 65 years old (Jiao 2018). With the aging of China's population, the elderly population has become the largest demand for health care services, and its health needs and medical security have become the hotspots of all circles (Chen and Xu 2011). At the end of 2018, China's internet penetration rate reached $59.6 \%$, and the number of users reached 829 million. However, aged users over 60 only accounted $6.6 \%$ of the internet users (CINIC 2019).

The introduction of mobile applications for health or medical dimensions was introduced late to China in 2011. However, since 2011 digital health applications have developed to include "Safe Doctor," "Meiyou" and "Xin Yang" (Chen 2018). WeChat dominates the mobile application scene with more than $80 \%$ of smartphone users in China deploying it. WeChat not only has social functions, but also features mobile health — such as pushing health information, making appointments, etc. The mobile health function of WeChat is predominantly used by middle-aged and older adults to follow health-related public accounts, discuss health problems in WeChat groups, as well as forward relevant health pushes, among others, which facilitates the information flow and exchanges among middle-aged and elderly people in China (Xu et al. 2018).

Simultaneously, the Chinese family structure has undergone a large change in recent decades with the majority of families transformed from an extended family structure (i.e., grown children living with older parents) to a nuclear structure where grown children live on their own (Gao et al. 2015). In this phenomenon, the older adults and their grown-up children often live a long distance apart and can only communicate with each other through mediated channels. In major metropolitan cities like Beijing and Shanghai, older adults are more likely to be economically independent and the co-residence of older people with adult children is declining (Zimmer et al. 2007; Logan and Bian 1999). According to a national survey on the living status of older adults, the average rate of the "empty nest" (KongChao) family has reached $49.7 \%$ in China's urban areas, with a $7 \%$ increase since 2000 (China National Committee on Ageing 2007). Given these factors, 
mobile-based social media platforms like WeChat have become a crucial channel for intergenerational caring and emotional support among longdistance family members across China.

China's current mobile-health platform can be classified into five types according to their functional characteristics-medical product e-commerce platform, professional information inquiry platform, medical consultation platform, sub-function function platform, health management and health care platform (Prospective Industry Research Institute; Wang and Wu 2014). In terms of technology development, studies in China have established a chronic disease management software model for hypertension patients to analyze user data (Qi 2017). Li Yangzi developed a telemedicine monitoring mobile medical platform based on the Android platform. Patients can conduct an inspection report inquiry, online diagnosis and treatment, and obtain health guidance on the platform $(\mathrm{Li}$ 2014). Xing Jin (2017) introduced the mobile medical system and mobile doctor assistant of Xuanwu Hospital of Capital Medical University (Jin and Fei 2007).

In user behavior research, some scholars have explored the influential factors of mobile health service acceptance behavior of middle-aged and older people in China. The results show that the vast majority of middleaged and older people have some anxiety about new technologies, which negatively affects their adoption intention to mobile health. Perceived ease of use in the process of implementing mobile health services has proven to be an important factor in influencing the adoption of mobile medical technology, which in turn, emphasizes the improvement of convenience and usability are needed to eliminate the anxiety and worries of middleaged and old users on new services (Mo and Deng 2015). For example, Liu Yongjun's research explores factors of mobile medical payment diffusion. In a discourse analysis of the website Hao Daifu (a popular online medical platform), Zhang Xiaofei established an online medical service adoption model and found that medical habits, silent costs, conversion costs and privacy protection create a certain hindrance to users' practice of online medical services (2014).

Sun et al. (2016) also focus on the development trends in Mobile Health and its clinical applications for the prevention and treatment of diseases, especially on the operation model of m-Health. They suggest the unified practice doctors' model, in which all of the doctors do not need to provide face-to-face services for patients (Sun et al. 2016). In China, Mobile health service app such as Chunyu Doctor has been studied to show its ability to enable general users to look up symptoms or to consult with professional 
doctors free of charge, as well as allowing professionals to communicate with health consumers.

Many new models of human-computer interaction (HCI) have been launched in various parts of China to respond to aging populations. Wuzhen has established an $\mathrm{O}_{2} \mathrm{O}$ platform for the aged care community to provide home-based early warning, emergency assistance, and health management services for the elderly and families. The online platform is mainly for the elderly to install smart home care equipment, remote health care equipment, SOS calls and alarms, and to use Alibaba Cloud server and WeChat for remote management.

The first "virtual nursing home" in Xi'an was launched in Lianhu District in March 2018. This is defined as the "nursing home without walls." Through the call center, it provides socialized old-age service subscription, planned appointment, service scheduling and Service supervision for the elderly groups in need (Zhao 2018). The need to design for complex sensory dimensions for older adults is vital-especially in terms of declining mobility, eye sight, and hearing impairments (Xu 2016). The use of robots for social interaction and mundane activities is starting to emerge — but only nascently when compared to Japan.

In fieldwork with our older adults, there was little understanding into how locative media within the apps functioned. However, many were concerned with perceived notions of privacy and trust. As noted in earlier chapters, the notion of privacy was culturally-specific - Japan had its own understandings of privacy that differed from the Chinese or Australian participants. Also, the significance of intergenerational understandings was also heightened as they were unidirectional. Often older adults were informally taught by their adult children, in particular ambient ways of being with the media that they were not necessarily attuned to.

Let us begin with our older adult participants. In Shanghai, popular digital health applications usage and attitudes among the older adults include WeChat sports and Xiaomi bracelet (self-track monitor). 51-year-old Li Wei was a government official in Suzhou. While Li Wei used a Xiaomi bracelet for a short period for tracking his personal health, he found that it wasn't very accurate and so he changed to WeChat sports. Li Wei said confidently that he didn't feel the need to use other apps because he was still very healthy.

Li Wei checked into the WeChat sports app at least once a day. This app kept track of his exercise and gamified it through ranking among friends. Li Wei's daily exercise was subject to the weather-if the weather was cold, he walked 6 ooo steps a day; when the weather was warm, he could walk 
12,00o steps each day. He admitted that the app changed his lifestyle habits and how he viewed health in an everyday context. Before using WeChat sports, he decisions to exercise were based only on his personal habits, like walking for one hour each day. After using WeChat sports, he made use of the app to monitor his exercise record and this became his "new habit." If he didn't walk someday, or if the walk number didn't meet his standard step count (e.g., 1200o), he felt that something was amiss.

However Li Wei has his doubts about other digital apps-especially self-tracking apps. He also commented that people should be mindful of "being kidnapped" by technology. When asked to explain further, Li Wei said, "when the digital is involved in our lives, other non-digital aspects of the body can be ignored. Some people will become reliant on digital indicators-like being kidnapped. If the indicators are not normal, we might feel more pressure, so we need to balance well."

For 54-year-old mother Biyu, hospital apps were useful to download when needing to see a doctor. As Biyu noted "for example, if I want to go to Zhongshan Hospital to see a doctor, I will download the Zhongshan Hospital app to get a registration number and make an appointment, which is quite convenient." In addition to hospital apps, the WeChat public account platform has become another popular channel for the Chinese older adults to make an apportionment to see a doctor. Biyu preferred using hospital apps as she was afraid to disclose privacy on WeChat. She also tried some self-tracking and testing apps—-like blood pressure meter apps—but she had concerns about the accuracy of the digital health applications. For instance, she did not trust the accuracy of the blood pressure app. "Compared to these apps, I trust the tests and measurements from traditional hospitals more," explained Biyu.

In fieldwork, there was a great discrepancy between young and older people attitudes towards digital health mobile apps. 69-year-old Aunt Chen said that she preferred to go to the hospital for regular registration and checkups, while her daughter favoured registration and checking on the WeChat platform. Biyu believed that while digital health was promising for young people, it was less realistic for older people. "In fact, many of us still like traditional ways - for example, I have learned how to pay by WeChat, but I am still paying with my wallet... Many of my friends in this generation feel that it useful to have digital options but we would hate for it to be the only option."

Increasingly WeChat plays a central role in many aspects of Chinese everyday life. Health information is no exception. There are many ways people can obtain information-WeChat group, public accounts, and moments. 
For Li Wei, "Now I am getting older, so I pay a lot of attention to health information. I can't completely control my mouth, but I try my best to keep a light diet and eat more whole grains. So, I need to know more knowledge about how to make a healthy eating and lifestyle." He subscribed to some health-based WeChat public accounts_-including "Wen Xiaoshu says" and "a guide to make a healthy life" — which sent him a notification every day.

Li Wei also joined some health knowledge groups via the introduction of friends — such as "Dadao Medical Center" and "Suzhou Health Sharing Group" - from which he also received updates about how to maintain a healthy life. Li Wei said that some professors and doctors were also active in these groups, helping to solve people's questions and inquiries, which he felt was quite useful and efficient. He also often forwarded and shared this information and knowledge to his own family group. Although he found these messages quite rich, he also doubted their credibility. He noted, "these messages are not entirely accurate, and even some are rumors." Li Wei thought it to be very important to check the health information but also admitted the difficulty for older people. Regarding the influence of WeChat channels, Li Wei said:

For much older groups like those are over 70 or 80 , the new media has no influence on them. However, for our age (50-60), the influence nowadays is still relatively large. Digital media like WeChat public accounts and groups are the main channel for me and my colleagues to know about the health information. And secondly, we can also exchange our experience about health issues... For example, cancer and diabetes patients can build a group specifically to organize some activities to discuss the current treatment methods, similar to the offline clubs and associations, which can helpful.

WeChat also plays an important role in informal ways of caring at a distance. This care can take the form of everyday sociality in helping with healthcare issues. Li Wei had 6oo-700 WeChat friends and 40-50 WeChat groupsincluding classmate groups, family groups, activity groups and co-worker groups. Talking about WeChat groups, Li Wei believed that the family group promoted long-distance communication between family members and facilitated the guidance and care with his daughter. Li Wei usually sent articles to his daughter, mainly about social value orientation and health information, in hopes that his daughter would pay more attention to health. He also utilized WeChat video once every few days with his daughter who was studying in Hong Kong. 


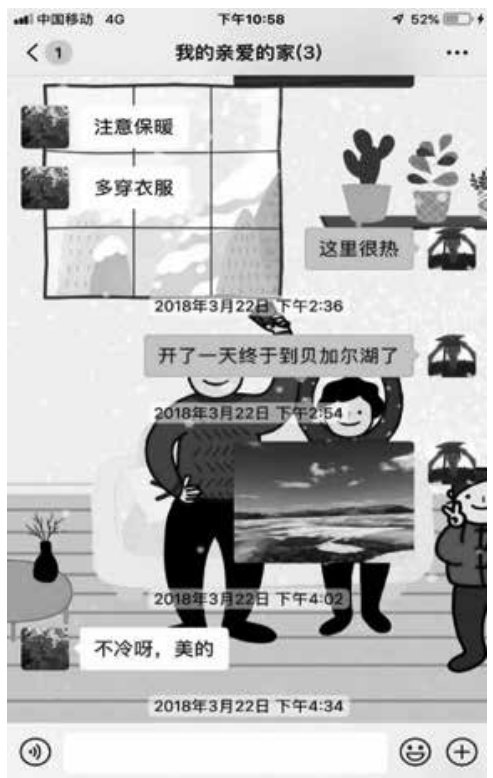

Figure 9.5: Screenshot of Li Wei's family group chat

Li Wei said that his wife was more actively involved his daughter's life — she asked her daughter more questions about her everyday life, taught her to cook through WeChat, reminded her about weather changes when she would need to travel home early. Once, through the remote guidance on WeChat, the daughter actually surprised them by making a table dish of garlic, cucumber, fried beans, braised prawns, steamed fish, etc. Li Wei was very happy and praised his daughter on WeChat. "Take this opportunity to practice cooking, and I look forward to your cooking skills when you go home."

Care and watching is often unidirectional. Adult children also use social media to watch their parents' lives and keep a friendly eye on them. As the only child, their 24-year-old daughter would also use WeChat to keep abreast of her parent's lives and health. She was worried that her parents were lonely when she was studying abroad. Therefore, she often sent updates to her family through WeChat, including photos and interesting stories. "I will let them know what I am doing every day, and it is another companion to them," explained Li Wei's daughter. This story of the use of WeChat's for care at a distance is common in contemporary China.

Different from Li Wei 's family, Biyu rarely sent health information to her son or to her family group. "I don't want to bore my son. I prefer to send positive information." Biyu explained that she seldom sent health 
information to her son because it was difficult to judge the credibility of much of the health information online. She also suspected that she had been blocked by her son because she couldn't see her son's WeChat moments. "I think he must have grouped me into a special group and blocked me from some content. But I didn't ask him about it." She explained her special communication model with her son, "Only when I have something urgent to communicate, will I make contact."

Aunt Chen said that WeChat had become one of the most important bonds to maintain family ties: "This kind of caring is very important, and it keeps the family together... For example, if I do not send any WeChat news to my daughter, my daughter will worry and will immediately give me a video call to confirm and vice versa." If there was any problem in daily life, Aunt Chen would also inform her daughter through WeChat, especially relating to situations about health status.

For example, recently, Aunt Chen got up and found that the towel she used had blood on it. After thinking for a while, she immediately took a photo and sent it to her daughter through WeChat. They talked through what it could be, problem-solving together. This was a typical long-distance health communication between two generations via WeChat. "My daughter was afraid to see the pictures and worried about whether there was something getting worse in my body. She kept checking my situation and gave me suggestions." This concern from her daughter made Aunt Chen feel better. She believed that WeChat is not only an essential tool for her family to express caring but also, for informal modes of healthcare.

As we saw in our Shanghai fieldwork, generational differences in attitudes towards data and health prevailed. Older adults, while using WeChat health discussion groups and hospital apps to book appointments, were clear that they didn't want the technology overtaking face-to-face care. Here, their thoughts echoed the findings in Pols' telecare study about the role of technology to enhance, not replace, face-to-face care (2012). Our younger participants were much more active in their use of tracking apps for self-care and were keen users of WeChat for familial care at a distance.

\section{Careful Apps in Melbourne}

Unlike Tokyo and Shanghai which saw main social media LINE and WeChat being used to not only care at a distance but also to choreograph ways of thinking about data and health, in Melbourne we find many of 
our participants using a diversity of media and techniques. Returning back to Jasmine, we find a participant whose practices have been greatly affected by the Cambridge Analytica debacle. After being hacked she is now vigilant about privacy settings for herself and her mum. As Jasmine noted:

My mobile media practices — that's my laptop, my tablet, and my mobile phone-have changed quite a bit... My phone, I don't use my phone as much; I don't check it as regularly. I still check it throughout the day, but I definitely used to scroll through Facebook a lot more. I took the app off my phone-after Cambridge Analytica and all of that stuff that happened last year. My mum's account was also hacked, and somebody started contacting her friends-I used that as an excuse to go through her phone and her Facebook profile and my Facebook profile to de-friend a lot of people and to just tighten down my security settings... At first, that was quite mentally difficult (without Facebook app), because I had to demarcate, OK, yes, you can do this; no, you have to stop, no you have to turn this off, no you can't use that. So that was a mentally exhausting to try to manage, but after a little while it became good habits.

When discussing her changes in her media practices, Jasmine reflected upon the way in which generation shapes media use. For Jasmine, she viewed mobile media as an important part of older generations having social connection-especially in the case of her mum. As Jasmine said:

I'm mid-3os and grew up in a time where we didn't have internet, and then we did have internet, and then we had mobile internet. So, I think for our generation, we've got a mix of addiction, discerning use, built into the routines in a way that we don't really think about it. So, I just hope that there will still be positive routines around social and mobile media use. My parents' use is different. For my mum, I think social media and her tablet has been great for her. She's still working, so when she comes home from work, she's still got her friends overseas, her relatives overseas that she chats with or she sees their posts. I think devices are good for aging populations in terms of diminishing social circles and less activities to do. I think they're a good source of company.

For Jasmine, the generational differences between her mum and her own practices were very much in terms of social connection. This importance 
of social connection had been a key aspect in aging well. For Jasmine, WhatsApp was crucial in keeping connected with her family in Australia and overseas. She observed:

We also have a family WhatsApp group, and that's a touching base, that's well wishes; it was just Chinese New Year, so we sent some images for that. So, yeah, I think they're gentle, just touching base with images and organization to catch up, and things like that. So that will be our informal care with social mobile media use. For care at a distance, yeah, for mainly that friend who lives in London, and it's the banter, humor, gossip, images; I think we also use Instagram quite a bit together. We direct message each other with other people's posts that we find amusing, usually cat posts, or if there's make up, or fitness, or if we're planning a trip, an image from that destination we want to go to.

For Jasmine, self-tracking apps were not of much interest. She noticed that her younger family members - especially female - were active self-trackers and used many apps. She expressed concerned that some of this micro-managing of the body could lead to unhealthy body obsessions - reflecting "beauty apps" discussions by Ana Sofia Elias and Rosalind Gill (2017). As Elias and Gill argue, such apps "offer a technology of gender which brings together digital self-monitoring and postfeminist modalities of subjecthood" in ways that are neoliberal $(2017,59)$. In building on the work in feminist surveillant studies they argued that such gendered self-tracking apps create "intensification, extensification and psychologization of surveillance" (Ibid.).

Indeed, much of our discussions with Jasmine - as with other Melbourne participants - foreground more ambivalence towards apps than in Tokyo and Shanghai. As Jasmine noted, whilst she and her friends had made a concerted effort to "pull back" from apps and datafication, Jasmine recognized that the future would be even more "datafied." As she noted:

I think there'll be a lot more interventions. I think there'll be a lot more hard-selling of apps, either to collect data, or to push a certain kind of healthy lifestyle. And those, I think, will become normalized as well. I'll probably download some stuff and then either embrace them into my routines or reject them [...] So, I think there will be a lot more interventions into pushing people to maintain healthy lifestyles and to collect data on them, and then these sorts of digital interventions will be normalized so much they become invisible, like social media was a few years ago. But now, a bunch of us have pulled back from that social media use as well. 
Like Jasmin, father Damian also noticed a continued growth when he used WhatsApp for discussions with family and friends to keep constantly connected. He saw the role of data in everyday life as a "double edged sword" and thought that the technology made for more frequent but shallower connections. As Damian noted:

Yeah, I think it's a double-edged sword and I don't know which way it'll go. It simultaneously connects and disconnects people. So, on the one hand, people have I've started to realize is that they are so connected with so many people by seeing them on Facebook. And yet it feels like people are catching up face to face less. We are all so busy.... Technology makes us feel like we need to busier and then allows us to fill in the absences with Likes. So, I've just got ridiculously wide circles of relatively shallow friendships with lots of people.

For Damian, the future of data in his and his family life involved the need for media literacy. As he observed:

I think that there might be some sort of space to educate people and give them really concrete strategies for how they engage with their technology to make sure that they're using their technology, not vice versa.

For 50-year-old Maria, wearable technologies like the Apple Watch had "released" her from her phone. She commented on how she was able to keep track of her fitness - which was important to aging well-without much effort. Maria was so happy with the Apple Watch that she had bought her 70-year-old mother one too-and then spent a week teaching her interstate mother how to use. Maria found comfort in features like heart rate monitoring apps-knowing that if a problem arose for her or her mother others could be alerted. She wondered if such conditions as dying from a heart attack could be avoided with such monitoring devices. Six months on from the purchase, Maria still received calls from her mother about how to work something or how to fix the Apple Watch. Maria joined her mother to the fitness app Strava so they could compare walks co-presently. As Maria noted:

My mum and I loved walking together. But being interstate means we can't do that very often. But having us both on Strava means we can give each other kudos and comment on each other's walks to give encouragement as an excuse for a conversation. I will ask her about what the walk was like.... 
Something that the Strava trail doesn't really show. It also makes me feel good that I know my mum is still fit and active. I think she will live to 100.

For 6o-year-old Amy, apps like WhatsApp were important in maintaining social connection with friends. It's often used to coordinate a social event with key friends, or to talk about key interests like films. While Amy's adult children used a lot of media and have taught her to use technology like iPads, she saw the dominance of mobile media slowing down. As Amy said:

There was a time when the kids were always with their phones, constantly on screens, texting each other while in the same room. I guess young people always find ways to challenge older generation's ideas and beliefs. But I have noticed a pull back from those behaviours-especially given all the stories about fake news and Facebook hacking. It's good to see some reflection. Well, at least it appears that way! My daughter recently showed me how my smartphone tracks my walking (default Health app) which was an eye opener. I'm still unsure how much of my life is being "captured" by this device... and what it will mean after I pass away.

50-year-old Mark was deeply concerned about data trails and digital legacy. In particular, he was worried about his parents who had started to use apps like Facebook on their phone to keep in contact with his sister overseas. Mark worried that they weren't aware of the darker side of datafication. He frequently asked them not to post pictures and to be careful what things they recorded on Facebook.

For Mark and his friends, being mindful of how their data could be used against them while they were alive, and also dead, was of major concern. When completing his first will Mark ensured he had a digital legacy component to it so as to ensure that his data could be accessed by loved ones, and not owned and reappropriated by corporations. This area of digital legacy is a growing area of interest and concern (Cumiskey and Hjorth 2018; Kaskett 2019).

In the Melbourne fieldwork, the use of apps for informal or formal health was less prevalent. However, the use of apps for informal care (at a distance) remained salient across the three sites. Here we can see the different ways in which health and care are manifested in everyday life subject to notions of trust. In sum, they are about quotidian notions of care and health shaped by generational, cultural and linguistic contexts. In particular, in Melbourne we noticed the biggest impact of the Cambridge Analytica debacle with many like Jasmine deleting their Facebook app on their phone and being 
more mindful of the darker side of quotidian datafication. In all locations, generational perceptions differed in terms of trust and understanding. But more research is needed to be done in this dynamic area.

\section{Conclusion}

In this section of the book we have explored some of the emergent ways our participants reflected upon social mobile media in everyday life through the ubiquitous rise of datafication through apps. In this assemblage we find various forms of ambient locative media. As we have discovered, while locative media was once about tracking through public spaces and places, through the rise of self-tracking we see the notion of locative media being recalibrated in ways that cater to more internal types of mapping. As we start to see, the rise of datafication can allow for us to explore the emotional and social cartographies of being in the world. This can be understood as feeling locative media - that is, the tacit and sensorial ways in which techniques of locative media-where location involves both internal and external cartographies-are being deployed in everyday life.

As this chapter has explored, feelings and perceptions about data and care differ across generations, cultural and linguistic contexts in ways that suggest more work is needed into the dynamics of Co-futuring Kinship. As we have argued through the kinship rubric, these practices are about a process of continuity rather than disruption to everyday rhythms. Having explored the beliefs and opinions of older adults in Chapter 8 we now can better understand how differences between and through the generations' use of media occur. We reflected upon how younger participants are co-futuring around applification and its relationship to family and kinship.

In this chapter we also started to hear participants' concerns around their data being used in unintended ways-in past (i.e. Cambridge Analytica debacle, NHK Fukushima disaster), present and in the future (data of the dead). In particular, participants voiced issues around what happens to their data and loved ones when they die. Notions such as digital legacy—having a provision in legal wills around ownership of data post-death — are becoming more and more apparent.

In fieldwork with participants over the three-year period, the rise of self-tracking and conspicuous journaling for parents at a distance played out. As discussed earlier, their digital media has increasingly played a pivotal role in navigating expressions of emotion, particularly intergenerationally when physical distance is an issue. As Lupton (2019) has noted, the rise of 
self-tracking has demonstrated how digital narratives can have material ramifications for users. She highlights that such QS practices make users more aware of their movement and its impact in the world.

For Lupton, feminist material approaches can provide insight into the ambivalences around self-tracking which include pleasure and burdensome elements. It has allowed for more "affective" and "sensory" understandings of movement, data and the everyday. Lupton points to ethnographic fieldwork around self-tracking in which digital devices can "monitor embodiment and selfhood, the mobilities and emplaced dimensions of these practices and the role of data visuality" (Lupton 2019, 68; Pink and Fors 2017).

In our fieldwork we have focused on the relationship between tracking and self-tracking intergenerationally as care at a distance. In this fieldwork we found how families and intimates could use data ambiently to keep a "friendly" eye on each other. Sometimes, these tacit forms of ritual and care moved ambiently from the background to the foreground in everyday life. And as we move towards datafied futures (Co-futuring Kinship), quotidian care at a distance can help us understand some of the ways in which data is playing out in intergenerational digital literacies around care.

\section{References}

Anonymous. 2011. Chunyu Doctors. http://www.chunyuyisheng.com/. Accessed 2 March 2018.

Akiyama, Hiroko. 2010. "Choju jidai no kagaku to shakai no kousou." Kagaku 80 (1): 59-64.

Cabinet Office, Government of Japan. 2018. White paper on aging society 2018. http://www8.cao.go.jp/kourei/whitepaper/w-2018/zenbun/3opdf_index.html. Accessed 2 March 2018.

Chen, Youhua and Xu Wei. 2011. "The health status, welfare needs and prospects of the elderly population in China [J]." Population journal 2 (In Chinese).

China Internet Network Information Center. 2018. The 43th Statistical Report on Internet Development in China [EB/OL] (In Chinese), Report. http://www.cnnic. net.cn/hlwfzyj/hlwxzbg/. Accessed 2 March 2018.

China National Committee on Ageing. 2007. A follow-up survey on China's elder population in urban and rural areas, Report. http://www.cnca.org.cn/ default/content/contentllxw.jsp?columnid=iroot $1000010001 \&$ articleid $=$ 4028e47d16ec2fd9011719a71bdg044e. Accessed 2 March 2018.

Chen, Yujia. 2018. Analysis of the factors affecting the adoption of mobile medical care by the public. Report. Dalian University of Technology (In Chinese). 
Elias, Ana Sofia, and Rosalind Gill. 2017. "Beauty surveillance: the digital selfmonitoring cultures of neoliberalism." European Journal of Cultural Studies 21 (1): 59-77. DOI: $10.1177 / 1367549417705604$.

Gao, Qin, Ebert, Daniel, Chen, Xing, and Yao Ding. 2015. "Design of a mobile social community platform for older Chinese people in urban areas." Human Factors and Ergonomics in Manufacturing \& Service Industries 25 (1): 66-89. DOI: 10.1002/ hfm.20523.

Han, Xinnian, Shi Wei, Li Hui, Wang Wei, and Meng Fanyuan. 2017. "Research on key technologies for the construction of regional medical information service platform [J]." The world's latest medical information digest 17 (71): 208-206 (In Chinese).

Iijima, Katsuya. 2016. "Early prevention strategies of 'frailty' based on local support network." https://www.mhlw.go.jp/file/05-Shingikai-1080100o-Iseikyoku-Soumuka/ ooo0135472.pdf. Accessed 2 March 2018.

Inagaki, Kana. 2019. "Japan's demographics make good case for self-driving cars." Financial Times. 17 July. https://www.ft.com/content/382aef5c-a7d7-11e9-984cfac8325aaao4. Accessed 2 March 2018.

Iwasaki, Fusako. 2017. "Elderly Person and Frailty." Quarterly journal of welfare society $36(2): 1-16$.

Jiao, Yahui. 2018. "Four questions test elderly medical care [J]." China Health July (In Chinese).

Kanawaku, Yoshimasa. 2018. "Koritsu-shi (Solitary Death) and its Actual Situation." Journal of Nippon Medical School 14 (3): 100-112. DOI:10.1272/manms.14.100.

Kiwaki, Nachiko and Arai, Yasutomo. 2015. "Social Isolation of Elderly People in Japan: From the Viewpoint of Family Paradigm Changes.” The bulletin of the Faculty of Human Life Sciences 52: 65-74.

Li, Yangzi. 2014. Research and Design of Mobile Medical System Based on Android Platform [D]. Report. Wuhan University of Science and Technology (In Chinese).

Liu, Weiying. 2014. System design of walking leg series elastic actuator. Report. Harbin Institute of Technology (In Chinese).

Liu, Xizhou. 2014. Design and Implementation of Mobile Medical Management System [D]. Report. Central China Normal University (In Chinese).

Liu, Yongjun. 2015. Study on the Influencing Factors of Mobile Medical Payment Based on Innovation Diffusion Theory [D]. Report. Southern Medical University (In Chinese).

Luo, Qihua. 2015. User-centered design of wearable sports health monitoring products for the elderly [D]. Report. Guangdong University of Technology (In Chinese).

Logan, John R., and Bian, Fuqin. 1999. "Family values and co-residence with married children in urban China." Social Forces 77 (4):1253-1282. DOI:10.2307/3005876. Lupton, Deborah (ed.). 2019. Self-Tracking, Health and Medicine. London: Routledge. 
Ministry of Health, Labour and Welfare of Japan. 2018. Abridged life table 2017. Report, https://www.mhlw.go.jp/toukei/saikin/hw/life/life17/dl/life17-14.pdf. Accessed 2 March 2018.

Mo, Xiuting, and Deng Zhaohua. 2015. "Empirical Study on the Acceptance Behavior of Mobile Health Services for Middle-aged and Old-aged Users in Wuhan." China Health Statistics 32 (2): (In Chinese).

Prospective Industry Research Institute. 2016-2021. China Mobile Medical Industry Typical Business Model and Construction Design Strategy Analysis Report (In Chinese).

Qi, Yumeng. 2017. Research and practice of a mobile medical software design method for patient compliance enhancement [D]. Report. Zhejiang University (In Chinese). Xing, Jin, and Fei Xiaowei. 2007. "The Architecture and Application of Mobile Medical System in Our Hospital [J]." Chinese medical equipment 32 (10): 122-25 (In Chinese).

Xu, Huan, Sun Sihang, Lin Wosa, and Yang Yang. 2018. "Feasibility analysis of mobile health based on smartphones to urban elderly." Journal of Preventive Medicine Information 34 (6): June (In Chinese).

$\mathrm{Xu}$, Junheng. 2016. Immersive interface design of the grip measurement software for the elderly [D]. Report. Zhejiang University (In Chinese).

Wang, Peng, and Wu Wei. 2014. "Discussion on the current status and future development trend of mobile Internet medical applications at home and abroad [J]." China Digital Medicine (In Chinese).

World Health Organization. 2016. Healthy life expectancy (HALE) at birth. Report. http://apps.who.int/gho/data/node.wrapper.imr?x-id=66. Accessed 2 March 2018.

$\mathrm{Wu}$, Rusong. 2012. Design of interactive TV interactive interface for urban elderly [D]. Report. Jiangnan University (In Chinese).

Yamazaki, Ryuji, Shuichi Nishio, Hiroshi Ishiguro and Hiroko Kase. 2018. "Use of Robotic Media as Persuasive Technology and Its Ethical Implications in Care Settings." Journal of Philosophy and Ethics in Health Care and Medicine 12 (December): $45^{-58 .}$

Zhao, Chuanfang. 2018. "Discussion on the development of Internet + aged care service [J]." China Development, August (In Chinese).

Zhang, Xiaofei. 2014. Research on the obstacles to the adoption of online medical services based on the current deviation theory [D]. Report. Harbin Institute of Technology (In Chinese).

Zimmer, Zachery, Kwong, Julia, Fung, Xianghua, Kareda, Toshiko, and Tang, Zhe. 2007. "Child Coresidence among Older Adults Living in Beijing, China: Trends, Determinants and Transitions." In New Perspectives on China and Aging, edited by Ian G. Cook and Jason L. Powell, $5^{-28}$. New York: Nova Science. 